\title{
The effect of short term exposure to outdoor air pollution on fertility
}

Mireia González-Comadran 1,2, Bénédicte Jacquemin 3,4,5,6, Marta Cirach ${ }^{4,5,6}$, Rafael Lafuente7, Thomas Cole-Hunter ${ }^{4,5,6,8}$, Mark Nieuwenhuijsen ${ }^{4,5,6}$, Mario Brassesco ${ }^{7}$, Buenaventura Coroleu ${ }^{9}$ and Miguel Angel Checa ${ }^{1,2,10,11,12^{*}}$

\begin{abstract}
Background: There is evidence to suggest that long term exposure to air pollution could be associated with decreased levels of fertility, although there is controversy as to how short term exposure may compromise fertility in IVF patients and what windows of exposure during the IVF process patients could be most vulnerable.

Methods: This prospective cohort study aimed to evaluate the impact of acute exposure that air pollution have on reproductive outcomes in different moments of the IVF process. Women undergoing IVF living in Barcelona were recruited. Individual air pollution exposures were modelled at their home address 15 and 3 days before embryo transfer (15D and 3D, respectively), the same day of transfer (D0), and 7 days after (D7). The pollutants modelled were: $\mathrm{PM}_{2.5}$ [particulate matter (PM) $\leq 2.5 \mu \mathrm{m}$ ], $\mathrm{PM}_{\text {coarse }}$ (PM between 2.5 and 10 $\left.\mu \mathrm{m}\right), \mathrm{PM}_{10}(\mathrm{PM} \leq 10 \mu \mathrm{m}), \mathrm{PM}_{2.5}$ abs, and $\mathrm{NO}_{2}$ and NOx. Outcomes were analyzed using multi-level regression models, with adjustment for co-pollutants and confouding factors. Two sensitivity analyses were performed. First, the model was adjusted for subacute exposure (received 15 days before ET). The second analysis was based on the first transfer performed on each patient aiming to exclude patients who failed previous transfers.
\end{abstract}

Results: One hundred ninety-four women were recruited, contributing with data for 486 embryo transfers. Acute and subacute exposure to PMs showed a tendency in increasing miscarriage rate and reducing clinical pregnancy rate, although results were not statistically significant. The first sensitivity analysis, showed a significant risk of miscarriage for $\mathrm{PM}_{2.5}$ exposure on $3 \mathrm{D}$ after adjusting for subacute exposure, and an increased risk of achieving no pregnancy for $\mathrm{PM}_{2.5}, \mathrm{PM}_{\text {coarse }}$ and $\mathrm{PM}_{10}$ on 3D.

The second sensitivity analysis showed a significant risk of miscarriage for $\mathrm{PM}_{2.5}$ exposure on $3 \mathrm{D}$, and a significant risk of achieving no pregnancy for PM2.5, PM coarse and PM10 particularly on 3D. No association was observed for nitrogen dioxides on reproductive outcomes.

Conclusions: Exposure to particulate matter has a negative impact on reproductive outcomes in IVF patients. Subacute exposure seems to increase the harmful effect of the acute exposure on miscarriage and pregnancy rates. Nitrogen dioxides do not modify significantly the reproductive success.

Keywords: Acute exposure, Particulate matter, Nitrogen dioxide, $\mathrm{PM}_{2.5}, \mathrm{PM}_{10}, \mathrm{NO}_{2}$, Fertility, Pregnancy, Miscarriage

*Correspondence: macheca@hospitaldelmar.cat

12 Reproductive Medicine Division at Hospital del Mar de Barcelona, Passeig Marítim 25-29, 08003 Barcelona, Spain

Full list of author information is available at the end of the article

\section{Introduction}

Air quality has risen in interest worldwide over the past decades. According to the World Health Organization (WHO), approximately $92 \%$ of the world's population [1] lives in areas where air quality exceeds their original author(s) and the source, provide a link to the Creative Commons licence, and indicate if changes were made. The images or other third party material in this article are included in the article's Creative Commons licence, unless indicated otherwise in a credit line to the material. If material is not included in the article's Creative Commons licence and your intended use is not permitted by statutory regulation or exceeds the permitted use, you will need to obtain permission directly from the copyright holder. To view a copy of this licence, visit http://creativecommons.org/licenses/by/4.0/. The Creative Commons Public Domain Dedication waiver (http://creativeco mmons.org/publicdomain/zero/1.0/) applies to the data made available in this article, unless otherwise stated in a credit line to the data. 
limits recommended for annual mean of particulate matter with a diameter of less than 2.5 micrometers $\left(\mathrm{PM}_{2.5}\right)$ [2], affecting both developed and developing countries. Cities are often hotspots of air pollution, with Barcelona ranking among the top polluted cities in Europe.

In 2015, ambient $\mathrm{PM}_{2.5}$ was ranked as the fifth greatest mortality risk factor [3]. Between 4 and 9 million deaths were attributable to ambient air pollution, representing $7.6 \%$ of global deaths, and 103.1 million disabilityadjusted life-years [3].

There is extensive evidence regarding the effect of air pollution on cerebrovascular [3-5] and ischemic heart disease [3, 6-9], chronic obstructive pulmonary disease $[3,10,11]$, asthma $[12,13]$ other respiratory disorders $[3$, $5,14,15]$, and carcinogenicity $[3,16,17]$, among others [18-20].

The effects of long-term exposure to air pollution on fertility [21-25] and perinatal outcomes [26-32] are also well documented. However, there is some controversy in the published literature regarding the effect of shortterm exposure to air pollutants, and what phases during the reproductive process are women most vulnerable to this exposure. The heterogeneity in the study design, conducted among women undergoing IVF makes it more difficult to draw firm conclusions. Most published studies are retrospective, and there is little evidence from prospective trials. Some studies observed a decrease in pregnancy rate among women exposed to higher concentrations of nitrogen dioxide $\left(\mathrm{NO}_{2}\right)[33,34]$ and particulate matter 10 micrometers or less in diameter $\left(\mathrm{PM}_{10}\right)$ [33] during different phases of the menstrual cycle during the IVF treatment. Other studies have described increases in miscarriage rate associated with higher exposures to $\mathrm{PM}_{10}$ [33, 35]. Gaskins et al., instead, used proximity to major roadways to measure the exposure to pollutants derived from traffic emissions and observed lower reproductive success in women living closer to traffic roads. In addition, there is uncertainty as to how each pollutant individually compromises fertility and what are the most relevant windows of exposure to be assessed.

The current study aims to assess the effect that shortterm exposure to air pollution has on fertility, and what are the phases of the menstrual cycle that make women most vulnerable.

\section{Materials and methods Study design}

A prospective observational cohort study was designed to evaluate the effect of short-term exposure to air pollutants on fertility, using the IVF model to accurately assess the different phases of the menstrual cycle. Participants were recruited between January 2014 and January 2018.
Our study population comprised women living in the area of Barcelona, who underwent one or more IVF cycles at Hospital del Mar de Barcelona, CIRH (Centro de Infertilidad y Reproducción Humana) and Hospital Universitari Quirón-Dexeus. Oocyte donation cycles and cancelled cycles were excluded from the study. Upon recruitment and prior to the embryo transfer (ET), a questionnaire assessing environmental exposure was delivered to each participant. Women that did not deliver the questionnaire were also excluded.

This study was supported by the public funding Instituto de Salud Carlos III (PI13/00454).

\section{Data collection}

Exposure to environmental factors residential addresses as well as variables that have a detrimental effect of fertility were included in the questionnaire, such as smoking [36], demographic and socio-economic variables [37, 38], Body mass index (BMI) [39, 40], dietary habits [41], physical activity [42, 43] and lifestyle [44]. Regarding the dietary habits, a score was assigned to each participant based on data extracted from the questionnaire and following the validated brief Mediterranean diet screener (bMDS), which estimates the adherence to Mediterranean diet.

Data regarding the clinical diagnosis, and the IVF treatment as well as the reproductive outcomes were collected from clinical records. The reproductive outcome was measured by serum hCG test performed 10 days after the ET and the ultrasound performed 2 weeks after the hCG test and/or at any time during the first trimester. Women were classified based on their reproductive outcome: "no pregnancy", "miscarriage" and "clinical pregnancy". Miscarriage was defined as serum hCG level greater that $5 \mathrm{mUI} / \mathrm{ml}$, associated with a pregnancy loss occurring during the first trimester of pregnancy. Clinical pregnancy was determined by ultrasound examination during the first trimester.

\section{Exposure assessment to outdoor air pollution}

For acute exposure, mean concentrations of $\mathrm{PM}_{2.5}, \mathrm{PM}_{2.5}$ abs, $\mathrm{PM}_{10}$, PM coarse, $\mathrm{NO}_{2}$ and $\mathrm{NOx}$ were modelled at home addresses of each participant in different windows during the implantation process: a) during the 3 days before ET (3D), beginning of the secretory phase; b) the same day of the ET (D0), during the window of implantation; and d) during the 7 days after (D7), once the implantation process has begun. To estimate individual subacute exposure we calculated the average daily exposure during the 15 days before the ET (15D), which corresponds to the proliferative phase of the menstrual cycle.

The exposure estimates were obtained from the ESCAPE study (European Study of Cohorts for Air 
Pollution Effects) that is described elsewhere [45]. Briefly, the spatiotemporal exposure assessment approach was based on land use regression modeling following a standardized protocol. Residential addresses were obtained and geocoded. We estimated the daily concentration according to the windows described above for each address for each transfer. The temporal adjustment factor based on routine monitoring data was done according to ESCAPE guidelines [46].

\section{Laboratory air quality}

The IVF laboratory uses a centered high-efficiency particulate air (HEPA) system that supplies filtered air without particles to the IVF laboratory, as well as carbon filters to remove volatile organic compounds. Additionally, Coda ${ }^{\circledR}$ Inline ${ }^{\circledR}$ filters were placed between the carbon dioxide circuit and the incubators, and replaced every six months.

\section{Statistical analysis}

As each participant could contribute with more than one ET, and assuming similarities between the ET from the same participants, fitting traditional regression models would lead to false inferences, hence multilevel regression models were required $[47,48]$. Due to the characteristics of the outcome (categorical) a multilevel logistic regression analysis was performed. Results from this model showed the risk of "miscarriage" and "no pregnancy" compared with the outcome "clinical pregnancy".

After an initial crude analysis to assess the effect of acute and subacute exposure to pollutants on reproductive outcomes, a priori we expressed all results relative to fixed increments in each pollutant, defined before analysis, $5 \mu \mathrm{g} / \mathrm{m}^{3}$ for $\mathrm{PM}_{2.5}$ and PM coarse, $10 \mu \mathrm{g} / \mathrm{m}^{3}$ for $\mathrm{PM}_{10}$ and $\mathrm{PM}_{2.5}$ abs, and $20 \mu \mathrm{g} / \mathrm{m}^{3}$ for $\mathrm{NO}_{2}$ and $\mathrm{NOx}$, as suggested by ESCAPE guidelines [46]. All analyses were performed using Stata software, version 13.1 (StataCorp).

Adjusted models were performed including known factors to have a detrimental effect on reproductive outcomes, variables that are associated with systemic inflammation and variables directly correlated with air pollution exposure. These confounders were age, BMI, physical activity, smoking intensity (measured in pack/day [49]), adherence to Mediterranean diet, socioeconomic status, number and quality of the embryos transferred, and the type of endometrial preparation (stimulated cycle versus natural or artificial cycle).

We performed two sensitivity analyses. First, the model for each pollutant was adjusted for the subacute exposure received during the proliferative phase, received during the 15 days before ET. The rationale behind this analysis is that some groups have observed a different response to the exposure of air pollutants among individuals with different basal levels of systemic inflammation [50, 51]. Hence the effect of air pollutants around the time of the ET could be influenced by cumulative effect of the exposure received during the proliferative endometrial phase, serving as a susceptibility factor.

Second, we analyzed the results including only the first transfer for each patient using classical logistic regression model, excluding patients who failed previous transfers for reasons that could bias our results and that were not controlled by the confounders included in the model.

Models evaluating the effect of particulate matter were adjusted for $\mathrm{NO}_{2}$, and models evaluating nitrogen oxides $\left(\mathrm{NO}_{2}\right.$ and $\left.\mathrm{NOx}\right)$ were adjusted for $\mathrm{PM}_{2.5}$. The goal was to assess the association between particulate matter and nitrogen oxides in the reproductive outcomes. Prior to this analysis, a potential correlation was addressed with the Person's correlation coefficients, and high correlations were assumed for coefficients higher than 0.7.

We expressed all results relative to fixed increments in each pollutant, defined before analysis, $5 \mu \mathrm{g} / \mathrm{m} 3$ for $\mathrm{PM}_{2.5}$ and PM coarse, $10 \mu \mathrm{g} / \mathrm{m} 3$ for $\mathrm{PM}_{10}$ and $\mathrm{PM}_{2.5}$ abs and 20 $\mu \mathrm{g} / \mathrm{m} 3$ for $\mathrm{NO}_{2}$ and NOx. All analyses were fit using Stata software, version 13.1 (StataCorp).

\section{Ethics approval}

Ethics approval was obtained (no. 2013/5249/I) from the Clinical Research Ethical Committee in Parc de Salut Mar, Barcelona, Spain.

\section{Results}

One hundred ninety-four patients were included in the study, that contributed with 486 embryo transfers.

The mean age was $36.9 \pm 4.02$ years, mean BMI was $22.97 \pm 3.69 \mathrm{~kg} / \mathrm{m}^{2}$, and mean Anti-Müllerian Hormone (AMH) was $2.45 \pm 2.62 \mathrm{ng} / \mathrm{mL} .29 .84 \%$ were fresh embryo transfers, and the mean number of embryos transferred per cycle was $1.56 \pm 0.52$. No differences were detected when comparing the mean number of embryos transferred in fresh versus frozen-thawed ET $(\mathrm{p}=0.61)$. The clinical pregnancy rate was $22.02 \%$ and clinical and biochemical miscarriage rates were 9.26 and $10.91 \%$, respectively.

An analysis of the patient's characteristics according to the results from the IVF cycles was performed. The number of MII oocytes retrieved and the number of fertilized oocytes were significantly lower among women who did not achieve a pregnancy as compared with women in the clinical pregnancy and miscarriage groups $(p=0.029$ and 0.0198, respectively). Results are described in Table 1.

During the study period, daily mean concentrations were modelled at their home addresses on concrete periods during the menstrual cycle $(15 \mathrm{D}, 3 \mathrm{D}, \mathrm{D} 0, \mathrm{D} 7$ and annual average), as registered on Table 2. For $\mathrm{PM}_{2.5}$ and 
Table 1 Patient's characteristics and IVF parameters

\begin{tabular}{|c|c|c|c|c|}
\hline & Clinical pregnancy & No pregnancy & Miscarriage & $p^{*}$ \\
\hline & Mean \pm standard d & edian (p25, p75) & & \\
\hline Maternal age, years & $36.44 \pm 0.33$ & $37.20 \pm 0.25$ & $36.39 \pm 0.44$ & 0.109 \\
\hline BMI & $22.60(0.36)$ & $22.91(0.22)$ & $23.62(0.41)$ & 0.120 \\
\hline Normal weight (18-24.9 kg/m2) & $65(69.15)$ & $177(79.02)$ & $69(74.19)$ & 0.187 \\
\hline Overweight (25-29.9kg/m2) & $16(17.02)$ & $33(14.73)$ & $16(17.20)$ & \\
\hline Obesity ( $\geq 30$ kg/m2) & $3(3.19)$ & $7(3.13)$ & $5(5.38)$ & \\
\hline Active smokers (\%) & $16(14.29)$ & $42(15.50)$ & $17(16.50)$ & 0.990 \\
\hline Smoking status (pack/day) & $0.30(0.20,0.55)$ & $0.40(0.25,0.60)$ & $0.50(0.30,0.50)$ & 0.880 \\
\hline Low socio-economic status & $43(41.35)$ & $114(46.34)$ & $58(53.19)$ & 0.246 \\
\hline Sedentarism & $76(68.47)$ & $208(76.75)$ & $73(70.87)$ & 0.332 \\
\hline Mediterranean diet (score) & $14.5(15,20)$ & $17(15,19)$ & $17(16,20)$ & 0.294 \\
\hline Ovarian stimulation & & & & \\
\hline Agonist (\%) & $19(16.96)$ & $51(18.82)$ & $16(15.53)$ & 0.738 \\
\hline Antagonist (\%) & $93(83.04)$ & $220(81.18)$ & $87(84.47)$ & \\
\hline Duration of stimulation, days & $11(9,12)$ & $11(10,12)$ & $11(10,12)$ & 0.786 \\
\hline No. MII Oocytes retrieved & $8(6,11)$ & $7(4,11)$ & $9(5,14)$ & 0.029 \\
\hline No. Embryos fertilized & $5(3,7)$ & $4(3,7)$ & $5(4,8)$ & 0.019 \\
\hline Fresh embryo transfers (\%) & $39(34.82)$ & $80(29.52)$ & $26(25.24)$ & 0.304 \\
\hline No. Embryos transferred & $1.59 \pm 0.51$ & $1.52 \pm 0.52$ & $1.64 \pm 0.52$ & 0.092 \\
\hline Blastocyst transfer (\%) & $30(26.79)$ & $31(11.44)$ & $23(22.33)$ & $<0.001$ \\
\hline
\end{tabular}

p25 25th percentile, $p 7575^{\text {th }}$ percentile, $n$ number, \% percentage, BMI Body Mass Index (expressed as kilograms / meter ${ }^{2}$ ), MII Metaphase II oocytes

The statistical analysis was performed using the $x 2$ test for categorical variables (expressed as $n$ (\%)), with one-way variance ANOVA for numerical variables with normal distribution (expressed as Mean \pm Standard deviation), and Kruskall Wallis test for numerical variables with non-normal distribution (expressed as Median $(\mathrm{p} 25, \mathrm{p} 75))$

${ }^{*} p$ values $\leq 0.05$ are considered statistically significant

Table 2 Exposure to air pollutants around the time of the embryo transfer

\begin{tabular}{lllll}
\hline & 15D & 3D & D0 & D7 \\
\hline $\mathrm{NO}_{2}(\mu \mathrm{g} / \mathrm{m} 3)$ & $36.30 \pm 15.38$ & $36.05 \pm 19.03$ & $38.01 \pm 21.90$ & $36.62 \pm 17.63$ \\
$\mathrm{NO}_{\mathbf{x}}(\mu \mathrm{g} / \mathrm{m} 3)$ & $62.13 \pm 32.29$ & $62.09 \pm 41.44$ & $65.41 \pm 46.17$ & $62.74 \pm 36.90$ \\
$\mathrm{PM}_{2.5}(\mu \mathrm{g} / \mathrm{m} 3)$ & $10.42 \pm 3.51$ & $10.35 \pm 4.62$ & $10.37 \pm 5.04$ & $10.57 \pm 4.19$ \\
$\mathrm{PM}_{2.5}$ abs $(1 \mathrm{unitat})$ & $1.92 \pm 0.82$ & $1.62 \pm 1.12$ & $2.02 \pm 1.29$ & $1.93 \pm 0.96$ \\
$\mathrm{PM} \mathrm{coarse}(\mu \mathrm{g} / \mathrm{m} 3)$ & $12.17 \pm 4.13$ & $12.14 \pm 5.40$ & $12.16 \pm 6.07$ & $12.43 \pm 4.97$ \\
$\mathrm{PM}_{10}(\mu \mathrm{g} / \mathrm{m} 3)$ & $21.87 \pm 6.52$ & $21.83 \pm 9.13$ & $21.90 \pm 10.41$ & $22.31 \pm 8.19$ \\
\hline
\end{tabular}

$N_{2}$ nitrogen dioxide, $N O x$ nitrogen oxide, $P M_{2.5}$ particulate matter (PM) with aerodynamic diameter $\leq 2.5 \mu$ m, $P M_{2.5}$ abs a surrogate of black carbon, $P M$ coarse $P M$ with aerodynamic diameter between 2.5 and $10 \mu \mathrm{m}, P M_{10} P M$ with aerodynamic diameter $\leq 10 \mu \mathrm{m}, 15 \mathrm{D}$ period of 15 days before the embryo transfer, $3 D$ period of 3 days before the embryo transfer, $D O$ the day of the embryo transfer, $D 7$ period of 7 days after the embryo transfer

Values are expressed as means \pm standard deviation, values for $\mathrm{PM}_{2.5 \text { absorbance }}$ expressed in $10^{-5 *} \mathrm{~m}^{-1} \mathrm{~m}$

$\mathrm{PM}_{10}$, average concentrations exceeded the levels recommended by the WHO Air quality guidelines [35], and for $\mathrm{NO}_{2}$, the average concentration was close to the upper limit of the permitted exceedances $(10 \mu \mathrm{g} / \mathrm{m} 3,20 \mu \mathrm{g} / \mathrm{m} 3$ and $40 \mu \mathrm{g} / \mathrm{m} 3$ respectively) for subacute and acute exposures [52].

The correlation analysis performed to test potential collinearity between pollutants, showed low correlation between pollutants, except for $\mathrm{PM}_{2.5}$ abs and $\mathrm{NO}_{2}$, which appeared highly correlated $(p>0.80) \quad$ (Table 3$)$. These results rule out the possibility of adjusting the effect of $\mathrm{PM}_{2.5}$ abs by $\mathrm{NO}_{2}$ exposure.

Acute and subacute exposure to particulate matter show a tendency in increasing miscarriage rate and reducing clinical pregnancy rate, although results are not statistically significant (data not shown).

In the first sensitivity analysis, an increased risk of miscarriage was observed compared with the clinical 
Table 3 Correlation between particulate matter and nitrogen oxides

\begin{tabular}{|c|c|c|c|c|c|}
\hline \multirow[t]{2}{*}{ Pollutant } & \multirow[b]{2}{*}{$\begin{array}{l}\text { Exposure } \\
\text { window }\end{array}$} & \multicolumn{4}{|l|}{$\mathrm{NO}_{2}$} \\
\hline & & $15 \mathrm{D}$ & $3 D$ & D0 & D7 \\
\hline \multirow{4}{*}{$\mathrm{PM}_{2.5}$} & $15 D$ & 0.48 & & & \\
\hline & $3 \mathrm{D}$ & & 0.56 & & \\
\hline & D0 & & & 0.51 & \\
\hline & D7 & & & & 0.45 \\
\hline \multirow[t]{4}{*}{$\mathrm{PM}_{2.5}$ abs } & $15 D$ & $0.88^{\mathrm{a}}$ & & & \\
\hline & $3 D$ & & $0.90^{\mathrm{a}}$ & & \\
\hline & Do & & & $0.91^{\mathrm{a}}$ & \\
\hline & D7 & & & & $0.91^{\mathrm{a}}$ \\
\hline \multirow[t]{4}{*}{ PM coarse } & $15 D$ & 0.55 & & & \\
\hline & $3 \mathrm{D}$ & & 0.56 & & \\
\hline & D0 & & & 0.56 & \\
\hline & D7 & & & & 0.59 \\
\hline \multirow[t]{5}{*}{$\mathrm{PM}_{10}$} & $15 D$ & 0.53 & & & \\
\hline & $3 \mathrm{D}$ & & 0.55 & & \\
\hline & D0 & & & 0.55 & \\
\hline & D7 & & & & 0.59 \\
\hline & & $\mathrm{PM}_{2.5}$ & & & \\
\hline \multirow[t]{4}{*}{$\mathrm{NO}_{2}$} & $15 D$ & 0.55 & & & \\
\hline & $3 \mathrm{D}$ & & 0.56 & & \\
\hline & D0 & & & 0.53 & \\
\hline & D7 & & & & 0.60 \\
\hline \multirow[t]{4}{*}{ NOx } & $15 D$ & 0.57 & & & \\
\hline & $3 \mathrm{D}$ & & 0.59 & & \\
\hline & D0 & & & 0.58 & \\
\hline & D7 & & & & 0.59 \\
\hline
\end{tabular}

$\mathrm{NO}_{2}$ nitrogen dioxide, $P M_{2.5}$ particulate matter (PM) with aerodynamic diameter $\leq 2.5 \mu \mathrm{m}, P M_{2.5}$ abs a surrogate of black carbon, $P M$ coarse $P M$ with aerodynamic diameter between 2.5 and $10 \mu \mathrm{m}, P M_{10} P M$ with aerodynamic diameter $\leq 10$ $\mu \mathrm{m}, \mathrm{NOx}$ nitrogen oxide, $15 \mathrm{D}$ period of 15 days before the embryo transfer, $3 D$ period of 3 days before the embryo transfer, $D 0$ the day of the embryo transfer, D7 period of 7 days after the embryo transfer

${ }^{\text {a }}$ High correlations indicate collinearity, and result in unstable estimates when adjusting models by co-pollutants

pregnancy rate during 3D and D0 for all PMs, reaching statistical significance for the exposure to $\mathrm{PM}_{2.5}$ three days before the embryo transfer (OR 1.84, 95\% CI $1.00-$ 3.39), as observed in Fig. 1. The risk of achieving no pregnancy was also increased for particulate matter, being significant or close to significance for exposures during 3D for $\mathrm{PM}_{2.5}$ (OD 1.60, 95\% CI 0.98 - 2.61), PM coarse (OR 1.81, 95\% CI $0.95-3.49$ ) and $\mathrm{PM}_{10}$ (OR 1.59, 95\% CI 1.02 - 2.47) (Fig. 2).

Neither the acute exposure to $\mathrm{NO}_{2}$ nor $\mathrm{NO}_{\mathrm{x}}$ showed significant associations with the risk of miscarriage or the risk of not achieving a pregnancy for any of the key days (Figs. 1 and 2).
In the second sensitivity analysis, that was based on the first embryo transfer cycle of each participant, a clear tendency on the reproductive outcomes is observed for particulate matter. With regard to the risk of miscarriage, a significant association is observed for $\mathrm{PM}_{2.5}$ during $3 \mathrm{D}$ (OR 3.80, 95\% CI 1.13 - 12.80). The risk of achieving no pregnancy was also significantly increased for $\mathrm{PM}_{2.5}$ during 3D (OR 2.72, 95\% CI 1.20 - 6.18), for PM coarse during 3D and D0 (OR 3.38, 95\% CI 1.04 - 10.92, and OR 2.37, 95\% CI $1.06-5.30$, respectively). For $\mathrm{PM}_{10}$, results were close to significance during 3D and D0 (OR 1.87, 95\% CI $0.97-3.58$ and OR 1.55, 95\% CI $0.99-2.41$, respectively). No effect was observed for $\mathrm{NO}_{2}$ or $\mathrm{NOx}$ on the reproductive outcomes when adjusting for $\mathrm{PM}_{2.5}$.

\section{Structured discussion/comment Principal findings}

Particulate matter could affect fertility. Particularly shortterm exposure during the onset of the secretory phase and at the time of the embryo implantation could have a detrimental effect on the endometrium reducing clinical pregnancy rate and increasing miscarriage rates. In addition, the cumulative exposure to air pollution received during the proliferative phase could confer vulnerability to increases of acute exposure.

\section{Results}

The results of this study show that acute increases in the exposure to particulate matter, particularly $\mathrm{PM}_{2.5}$ and $\mathrm{PM}_{10}$ during the onset of the secretory phase and around the time of the embryo implantation, have a negative effect on reproductive outcomes. An increase in the risk of miscarriage was observed at higher exposure to PMs, results that were only significant for $\mathrm{PM}_{2.5}$ at the onset of the secretory phase. Similarly, a decrease in pregnancy rate was also observed for PMs, particularly at the onset of the secretory phase and around the time of the embryo implantation, being significant or close to significance for $\mathrm{PM}_{2.5}$ and $\mathrm{PM}_{10}$ (Figs. 1 and 2). While, $\mathrm{NO}_{2}$ does not seem to have any significant effect on reproductive outcomes. The statistical analysis was performed adjusting for co-pollutants (particulate matter models were adjusted for $\mathrm{NO}_{2}$, and nitrogen oxide models were adjusted for $\mathrm{PM}_{2.5}$ ).

In a first sensitivity analysis, we explored the effect of subacute and acute exposures on reproductive outcomes, and whether this subacute exposure during the proliferative phase could interfere with the effect that acute exposure has on fertility around the time of the embryo implantation. Results from this analysis showed a global increase in the risks of both miscarriage and "no pregnancy" with respect to clinical pregnancy (Figs. 1 and 2, respectively) compared with that of the crude model and 

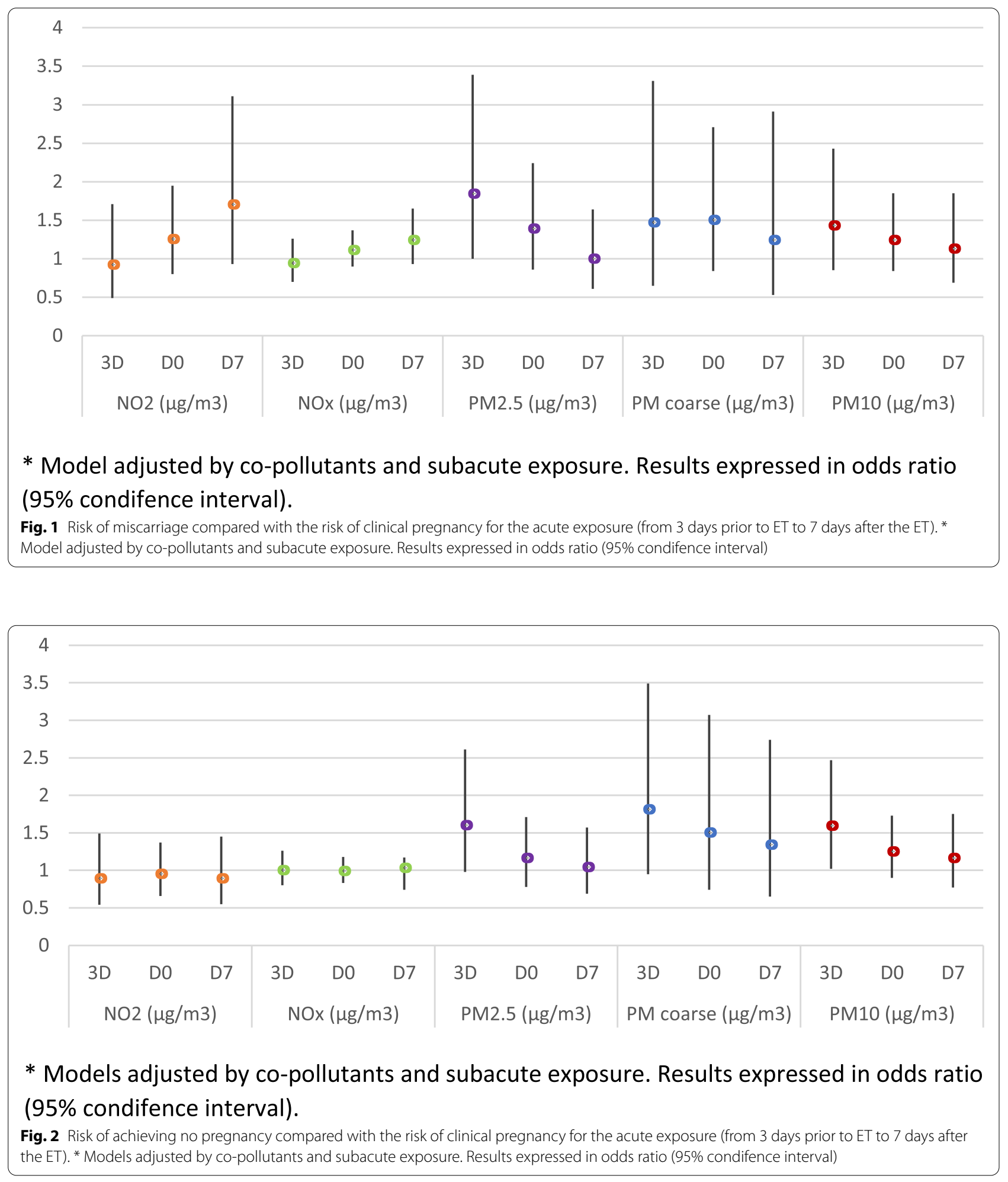

the one adjusted only for covariates (data not shown). These findings suggest that the cumulative exposure received during the proliferative phase of the endometrial cycle could serve as a susceptibility factor, modifying the effect of the exposure received around the time of the implantation. 
There is epidemiological evidence to suggest that longterm exposure to air pollution has a deleterious effect on reproductive life [21-23] and perinatal outcomes [26$32]$. There is also some evidence among women undergoing IVF to suggest that short-term exposure could impair reproductive outcomes [23]. Results from this study support the findings described in previous retrospective trials that have addressed this issue [21, 22, 33-35, 53]. The literature published is highly heterogeneous in terms of both the target population evaluated and the exposure periods analyzed, and although most authors evaluated exposures ranging from the early follicular development to the hCG test after embryo transfer [33-35, 53, 54], results reported are also conflicting.

\section{Clinical implications}

Women seeking for pregnancy who live in highly polluted cities could be advised to adapt their lifestyle to limit their exposure. Among women undergoing IVF, clinicians could consider to avoid ETs when peaks of air pollution are expected, recommend these women to go out for fresh air away from cities before the procedure, or even be advice to not naturally ventilate the home or vehicles, and instead use air conditioning when possible.

Air pollution is a major public health concern because of its ubiquity and known negative effect on health, and it has been identified as a worldwide health priority. However, global but also local public health measures are needed to reduce pollution and prevent these related harmful effects, in particular their effect on reproductive health, through public health policies in the field of pollution regulation, and limitations on traffic and fuel type, among others.

\section{Research implications}

The present study provides some insight on several aspects that have not been addressed yet in the previous studies, such as the effect that the cumulative exposure to air pollutants during the proliferative phase of the menstrual cycle has on fertility, and how this can modify the effect that acute exposure has on reproductive success.

This effect has been described by some authors [50,51], who reported a significantly higher effect of pollutants on markers of inflammation among individuals with elevated markers of basal inflammation. Indeed, an increase in the systemic inflammatory response during the proliferative phase could confer vulnerability by modifying the activation or suppression of genes in the endometrium during this phase, thereby modify the effect that acute exposure could have during the implantation process.

However, this concept of susceptible individuals needs to be explored in further prospective trials. In this regard, it is essential to identify subgroups with greater vulnerability to the harmful effect of pollutants, especially those under the effect of systemic inflammation. Of particular relevance, aspects related to lifestyle such as obesity, metabolic syndrome, sedentary lifestyle, and smoking, among others.

\section{Strengths and limitations}

This study has some limitations to consider; most importantly the sample size. In environmental epidemiology, there are many confounding factors, and estimates tend to be low hence the sample size needs to be large to be able to detect significant differences, even though our power calculation gave us power above $80 \%$ for $\mathrm{PM}_{2.5}$. Besides, there is potential bias in air pollution exposure model determinants, as well as selection bias of the population included.

Nevertheless, this study has strengths that need to be promoted. Analyzing the effect of pollutants among IVF women provided an opportunity to assess what moments during the menstrual cycle patients are most vulnerable, and gain insight into the mechanisms by which air pollutants impair fertility. Besides, the prospective nature of the study allows an accurate control of confounders associated to either reproductive success, systemic inflammation or exposure to pollutants. Moreover, models were adjusted for co-pollutants, allowing us to detect a greater effect of PM exposure when controlling for $\mathrm{NO}_{2}$. Finally, the hierarchical structure of the study population allowed a greater representativeness of what happens in clinical practice, increasing the external validity of the results in the general population seeking pregnancy.

\section{Conclusions}

This study shows that acute exposure to particulate matter has a negative effect on fertility particularly during the onset of the secretory phase and at the time of the embryo implantation, while exposure during the proliferative phase seems to increase the harmful effect of the acute exposure. $\mathrm{NO}_{2}$ does not seem to have any effect.

\footnotetext{
Abbreviations

IVF: In vitro fertilization; ET: Embryo transfer; $\mathrm{PM}_{2.5}$ : Particulate matter (PM) $\leq 2.5 \mu \mathrm{m}$ in diameter; $\mathrm{PM}_{\text {coarse }}$ : $P M$ between 2.5 and $10 \mu \mathrm{m} ; \mathrm{PM}_{10}: \mathrm{PM} \leq 10 \mu \mathrm{m}$; $\mathrm{PM}_{2.5}$ abs: $\mathrm{PM}_{2.5}$ absorvance refers to the soot content of $\mathrm{PM}_{2.5} ; \mathrm{NOx}$ : Nitrogen oxides; $\mathrm{NO}_{2}$ : Nitrogen dioxide; 15D: 15 days before the embryo transfer; 3D: 3 days before the embryo transfer; D0: The same day of the embryo transfer; D7: 7 days after the embryo transfer; ESCAPE: European Study of Cohorts for Air Pollution Effects; LUR: Land use regression; HEPA: High-efficiency particulate Air system; VOCs: Volatile organic compounds; WHO: World Health Organization; bMDS: Brief Mediterranean diet screener; hCG: Human chorionic gonadotropin; $\mathrm{CIRH}$ : Centro de Infertilidad y Reproducción Humana; BMI: Body mass index; AMH: Anti-mullerian hormone; MIl: Metaphase II oocytes; OR: Odds ratio; Cl: Confidence interval.
}

Acknowledgements

Not applicable 


\section{Authors' contributions}

Mireia González-Comadran: design of the work; acquisition of data, analysis and interpretation of data, drafting the manuscript and given final approval of the version to be published. Bénédicte Jacquemin: design of the work, analysis and interpretation of data, drafting the manuscript, revising and adapting the manuscript critically, and given final approval of the version to be published. Marta Cirach: acquisition of data, revised manuscript and given final approval of the version to be published. Rafael Lafuente: acquisition of data, revised manuscript and given final approval of the version to be published. Thomas Cole-Hunter: design of the work; revised manuscript and given final approval of the version to be published. Mark Nieuwenhuijsen: exposure assessment to air pollutants, acquisition of data, revised manuscript and given final approval of the version to be published. Mario Brassesco: acquisition of data, revised manuscript and given final approval of the version to be published. Buenaventura Coroleu: acquisition of data, revised manuscript and given final approval of the version to be published. Miguel Angel Checa: conception and design of the work, analysis and interpretation of data, revised manuscript and given final approval of the version to be published.

\section{Funding}

This study was funded by Instituto de Salud Carlos III (PI13/00454), and also received collaboration by AGAUR (Agency for Management of University and Research Grants, Generalitat de Catalunya, SGR 2017-2019). The funders had no role in the design or conduct of the study; collection, analysis and interpretation of the data retrieved; or preparation, review or approval of the manuscript.

\section{Availability of data and materials}

The datasets generated and/or analysed during the current study are not publicly available due the extension and complexity of the analysis, but are available from the corresponding author on reasonable request

\section{Declarations}

\section{Ethics approval and consent to participate}

Ethics approval was obtained (no. 2013/5249/I) from the Clinical Research Ethical Committee in Parc de Salut Mar, Barcelona, Spain.

\section{Consent for publication}

Not applicable

\section{Competing interests}

The authors declare no conflict of interest

\begin{abstract}
Author details
${ }^{1}$ Department of Obstetrics and Gynecology, Hospital del Mar, Barcelona, Spain. ${ }^{2}$ Barcelona Research Infertility Group, IMIM Institut Hospital del Mar d'Investigacions Mèdiques, Barcelona, Spain. ${ }^{3}$ Univ Rennes 1, Inserm, EHESP, Irset (Institut de recherche en santé, environnement et travail) - UMR_S 1085, F-35000 Rennes, France. ${ }^{4}$ Institute for Global Health (ISGlobal), Barcelona, Spain. ${ }^{5}$ Department of Experimental and Health Sciences, Universitat Pompeu Fabra, Barcelona, Spain. ${ }^{6}$ CIBER Epidemiología y Salud Pública (CIBERESP), Madrid, Spain. ${ }^{7}$ Centro de Infertilidad y Reproducción Humana (CIRH), BarceIona, Spain. ${ }^{8}$ Section of Environmental Health, Department of Public Health, University of Copenhagen, Copenhagen, Denmark. ${ }^{9}$ Hospital Universitari Quiron Dexeus, Salud de la Mujer Dexeus, Barcelona, Spain. ${ }^{10}$ Universidad Autónoma de Barcelona, Barcelona, Spain. ${ }^{11}$ Fertty, Clĺnica de Reproducción Asistida, Barcelona, Spain. ${ }^{12}$ Reproductive Medicine Division at Hospital del Mar de Barcelona, Passeig Marítim 25-29, 08003 Barcelona, Spain.
\end{abstract}

Received: 12 July 2021 Accepted: 24 September 2021

Published online: 06 October 2021

\section{References}

1. WHO. WHO releases country estimates on air pollution exposure and health impact. News release - GENEVA. 2016 [Citat 4 Jun 2020]. Disponible a: https://www.who.int/news-room/detail/27-09-2016-who-releasescountry-estimates-on-air-pollution-exposure-and-health-impact.
2. World Health Organization. Ambient (outdoor) air quality and health. 2018 [Citat 18 Sep 2018]. Disponible a: http://www.who.int/news-room/ fact-sheets/detail/ambient-(outdoor)-air-quality-and-health.

3. Cohen AJ, Brauer M, Burnett R, Anderson HR, Frostad J, Estep K, et al. Estimates and 25-year trends of the global burden of disease attributable to ambient air pollution: an analysis of data from the Global Burden of Diseases Study 2015. Lancet. 2017;389(10082):1907-18.

4. Stafoggia M, Cesaroni G, Peters A, Andersen ZJ, Badaloni C, Beelen R, et al. Long-term exposure to ambient air pollution and incidence of cerebrovascular events: Results from 11 European cohorts within the ESCAPE project. Environ Health Perspect. 2014;122(9):919-25.

5. Wichmann J, Voyi K. Ambient air pollution exposure and respiratory, cardiovascular and cerebrovascular mortality in Cape Town, South Africa: 2001-2006. Int J Environ Res Public Health. 2012;9(11):3978-4016.

6. Brook RD, Rajagopalan S, Pope CA, Brook JR, Bhatnagar A, Diez-Roux $A V$, et al. Particulate matter air pollution and cardiovascular disease: An update to the scientific statement from the American Heart Association. Circulation. 2010;121(21):2331-78

7. Wang M, Beelen R, Stafoggia M, Raaschou-Nielsen O, Andersen ZJ, Hoffmann B, et al. Long-term exposure to elemental constituents of particulate matter and cardiovascular mortality in 19 European cohorts: Results from the ESCAPE and TRANSPHORM projects. Environ Int. 2014;66:97-106.

8. Rajagopalan S, Al-Kindi SG, Brook RD. Air pollution and cardiovascular disease. J Am Coll Cardiol. 2018;72(17):2054-70.

9. Fuks KB, Weinmayr G, Foraster M, Dratva J, Hampel R, Houthuijs D, et al. Arterial blood pressure and long-term exposure to traffic-related air pollution: An analysis in the european study of cohorts for air pollution effects (ESCAPE). Environ Health Perspect. 2014;122:896-905 Public Health Services, US Dept of Health and Human Services.

10. Wang $C, X u$ J, Yang L, Xu Y, Zhang X, Bai C, et al. Prevalence and risk factors of chronic obstructive pulmonary disease in China (the China Pulmonary Health [CPH] study): a national cross-sectional study. Lancet. 2018;391(10131):1706-17.

11. Liang L, Cai Y, Barratt B, Lyu B, Chan Q, Hansell AL, et al. Associations between daily air quality and hospitalisations for acute exacerbation of chronic obstructive pulmonary disease in Beijing, 2013-17: an ecological analysis. Lancet Planet Heal. 2019;3(6):e270-9.

12. Jacquemin B, Siroux V, Sanchez M, Carsin AE, Schikowski T, Adam M, et al. Ambient air pollution and adult asthma incidence in six european cohorts (Escape). Environ Health Perspect. 2015;123(6):613-21.

13. McConnell R, Islam T, Shankardass K, Jerrett M, Lurmann F, Gilliland F, et al. Childhood incident asthma and traffic-related air pollution at home and school. Environ Health Perspect. 2010;118(7):1021-6.

14. Cai Y, Schikowski T, Adam M, Buschka A, Carsin AE, Jacquemin B, et al. Cross-sectional associations between air pollution and chronic bronchitis: An ESCAPE meta-analysis across five cohorts. Thorax. 2014;69(11):1005-14.

15. Kyung SY, Jeong SH. Particulate-matter related respiratory diseases. Tuberc Respir Dis (Seoul). 2020;83(2):116.

16. Hamra GB, Laden F, Cohen AJ, Raaschou-Nielsen O, Brauer M, Loomis D. Lung cancer and exposure to nitrogen dioxide and traffic: a systematic review and meta-analysis. Environ Health Perspect. 2015;123(11):1107-12.

17. Raaschou-Nielsen O, Andersen ZJ, Beelen R, Samoli E, Stafoggia M, Weinmayr G, et al. Air pollution and lung cancer incidence in 17 European cohorts: Prospective analyses from the European Study of Cohorts for Air Pollution Effects (ESCAPE). Lancet Oncol. 2013;14(9):813-22.

18. Cesaroni G, Forastiere F, Stafoggia M, Andersen ZJ, Badaloni C, Beelen $\mathrm{R}$, et al. Long term exposure to ambient air pollution and incidence of acute coronary events: prospective cohort study and meta-analysis in 11 European cohorts from the ESCAPE Project. BMJ. 2014;348(jan21 3):f7412.

19. Bourdrel T, Bind M-A, Béjot Y, Morel O, Argacha J-F. Cardiovascular effects of air pollution.

20. Guxens M, Ghassabian A, Gong T, Garcia-Esteban R, Porta D, Giorgis-Allemand $L$, et al. Air pollution exposure during pregnancy and childhood autistic traits in four European population-based cohort studies: The ESCAPE project. Environ Health Perspect. 2016;124(1):133-40.

21. Nieuwenhuijsen MJ, Basagaña X, Dadvand P, Martinez D, Cirach M, Beelen R, et al. Air pollution and human fertility rates. Environ Int. 2014;70:9-14. 
22. Mahalingaiah S, Hart J, Laden F, Farland LV, Hewlett MM, Chavarro J, et al. Adult air pollution exposure and risk of infertility in the Nurses' Health Study II. Hum Reprod. 2016;31(3):638-47.

23. Checa Vizcaíno MA, González-Comadran M, Jacquemin B. Outdoor air pollution and human infertility: a systematic review. Fertil Steril. 2016;106(4):897-904.e1

24. Wesselink AK, Kirwa K, Hatch EE, Hystad P, Szpiro AA, Kaufman JD, et al. Residential proximity to major roads and fecundability in a preconception cohort. Environ Epidemiol. 2020;4(6):e112.

25. Mendola P, Sundaram R, Louis GMB, Sun L, Wallace ME, Smarr MM, et al. Proximity to major roadways and prospectively-measured time-to-pregnancy and infertility. Sci Total Environ. 2017;576:172-7.

26. Burris HH, Just A, Elovitz MA. 241: Air pollution contributes to to spontaneous, but not medically-indicated, preterm birth risk. Am J Obstet Gynecol. 2020;222(1):S166-7.

27. Ashin M, Bilenko N, Friger M, Sergienko R, Sheiner E. 495: Exposure to ambient air pollution as a risk factor for low birth-weight. Am J Obstet Gynecol. 2018;218(1):S296-7.

28. Ashin M, Bilenko N, Friger M, Sergienko R, Sheiner E. 304: Exposure to traffic noise and ambient air pollution and the risk for preeclampsia. Am J Obstet Gynecol. 2018;218(1):S192.

29. Klepac P, Locatelli I, Korošec S, Künzli N, Kukec A. Ambient air pollution and pregnancy outcomes: A comprehensive review and identification of environmental public health challenges. Environ Res. 2018;167:144-59 Academic Press Inc.

30. Kahr MK, Suter MA, Ballas J, Ramphul R, Lubertino G, Hamilton WJ, et al. Preterm birth and its associations with residence and ambient vehicular traffic exposure. Am J Obstet Gynecol. 2016;215(1):111.e1-111.e10.

31. Pedersen M, Giorgis-Allemand L, Bernard C, Aguilera I, Andersen AMN Ballester F, et al. Ambient air pollution and low birthweight: A European cohort study (ESCAPE). Lancet Respir Med. 2013;1(9):695-704.

32. Williams K, Edwards S, Tassone E, Gray S, Swamy GK, Gelfand A, et al. Effect of air pollution (PM2.5 \& PM10) on low birthweight in North Carolina. Am J Obstet Gynecol. 2006;195(6):S213.

33. Choe SA, Jun YB, Lee WS, Yoon TK, Kim SY. Association between ambient air pollution and pregnancy rate in women who underwent IVF. Hum Reprod. 2018;33(6):1071-8.

34. Legro RS, Sauer MV, Mottla GL, Richter KS, Li X, Dodson WC, et al. Effect of air quality on assisted human reproduction. Hum Reprod. 2010;25(5):1317-24

35. Perin PM, Maluf M, Czeresnia CE, Nicolosi Foltran Januário DA, Nascimento Saldiva PH. Effects of exposure to high levels of particulate air pollution during the follicular phase of the conception cycle on pregnancy outcome in couples undergoing in vitro fertilization and embryo transfer. Fertil Steril. 2010;93(1):301-3.

36. Roth LK, Taylor HS. Risks of smoking to reproductive health: assessment of women's knowledge. Am J Obstet Gynecol. 2001;184(5):934-9.

37. Dribe M, Breschi M, Gagnon A, Gauvreau D, Hanson HA, Maloney TN, et al. Socio-economic status and fertility decline: Insights from historical transitions in Europe and North America. Popul Stud. 2017;71(1):3-21.

38. Culhane JF, Elo IT. Neighborhood context and reproductive health. Am J Obstet Gynecol. 2005;192(5 Suppl):S22-9.

39. Cardozo ER, Neff LM, Brocks ME, Ekpo GE, Dune TJ, Barnes RB, et al. Infertility patients' knowledge of the effects of obesity on reproductive health outcomes. Am J Obstet Gynecol. 2012;207(6):509.e1-509.e10
40. Jungheim ES, Moley KH. Current knowledge of obesity's effects in the pre- and periconceptional periods and avenues for future research. Am J Obstet Gynecol. 2010;203(6):525-30.

41. Gaskins AJ, Chavarro JE. Diet and fertility: a review. Am J Obstet Gynecol. 2018:218(4):379-89.

42. Gudmundsdottir SL, Flanders WD, Augestad LB. Physical activity and fertility in women: the North-Trondelag Health Study. Hum Reprod. 2009;24(12):3196-214.

43. Wise LA, Rothman KJ, Mikkelsen EM, Sørensen HT, Riis AH, Hatch EE. A prospective cohort study of physical activity and time to pregnancy. Fertil Steril. 2012;97(5):1136-42.e1-4.

44. Sharma R, Biedenharn KR, Fedor JM, Agarwal A. Lifestyle factors and reproductive health: taking control of your fertility. Reprod Biol Endocrinol. 2013;11:66

45. Eeftens M, Beelen R, De Hoogh K, Bellander T, Cesaroni G, Cirach M, et al. Development of land use regression models for PM2.5, PM 2.5 absorbance, PM10 and PMcoarse in 20 European study areas; Results of the ESCAPE project. Environ Sci Technol. 2012;46(20):11195-205.

46. Brunekreef B. Study manual ESCAPE European study of cohorts for air pollution effects. 2008. Disponible a: http://www.escapeproject.eu/ manuals/ESCAPE-Study-manual_x007E_final.pdf.

47. Austin PC, Goel V, van Walraven C. An introduction to multilevel regression models. Can J Public Health. 2001;92(2):150-4.

48. Raudenbush SW, Bryk AS. Hierarchical linear models : applications and data analysis methods. 2nd ed. Thousand Oaks: Sage Publications; 2002.

49. Nance R, Delaney J, McEvoy JW, Blaha MJ, Burke GL, Navas-Acien A, et al. Smoking intensity (pack/day) is a better measure than pack-years or smoking status for modeling cardiovascular disease outcomes. J Clin Epidemiol. 2017;81:111-9.

50. Lee H, Myung W, Jeong B-H, Choi H, Jhun BW, Kim H. Short- and longterm exposure to ambient air pollution and circulating biomarkers of inflammation in non-smokers: A hospital-based cohort study in South Korea. Environ Int. 2018;119:264-73.

51. Li W, Dorans KS, Wilker EH, Rice MB, Ljungman PL, Schwartz JD, et al. Short-term exposure to ambient air pollution and biomarkers of systemic inflammation: The Framingham Heart Study. Arterioscler Thromb Vasc Biol. 2017;37(9):1793-800.

52. World Health Organization. WHO Air quality guidelines for particulate matter, ozone, nitrogen dioxide and sulfur dioxide. Global update 2005. Summary of risk assessment. 2006 [citat 7 Feb 2020]. Disponible a: https://apps.who.int/iris/bitstream/handle/10665/69477/WHO_SDE_ PHE OEH 06.02 eng.pdf?sequence $=1$.

53. Perin PM, Maluf $\bar{M}$, Czeresnia CE, Januário DANF, Saldiva PHN. Impact of short-term preconceptional exposure to particulate air pollution on treatment outcome in couples undergoing in vitro fertilization and embryo transfer (IVF/ET). J Assist Reprod Genet. 2010;27(7):371-82.

54. Gaskins AJ, Hart JE, Mínguez-Alarcón L, Chavarro JE, Laden F, Coull BA, et al. Residential proximity to major roadways and traffic in relation to outcomes of in vitro fertilization. Environ Int. 2018;115:239-46.

\section{Publisher's Note}

Springer Nature remains neutral with regard to jurisdictional claims in published maps and institutional affiliations.

\footnotetext{
Ready to submit your research? Choose BMC and benefit from:

- fast, convenient online submission

- thorough peer review by experienced researchers in your field

- rapid publication on acceptance

- support for research data, including large and complex data types

- gold Open Access which fosters wider collaboration and increased citations

- maximum visibility for your research: over 100M website views per year
}

At BMC, research is always in progress.

Learn more biomedcentral.com/submissions 